\title{
Recorriendo instituciones: análisis del film Camino
}

\author{
Camino | Javier Fesser | 2008
}

\author{
Natacha Mateo" y Javier Mendizabal"* \\ Universidad Nacional de Mar del Plata
}

Recibido: 8 de mayo 2017; aceptado: 7 de septiembre 2017

\begin{abstract}
Resumen
Partiendo de entender el cine como una herramienta fundamental en el análisis social, es que este artículo pretende problematizar algunos aspectos de la sociedad actual y las instituciones que la sostienen. Puntualmente, desde algunos tópicos que propone el film Camino de Javier Fesser (2008), el objetivo de este trabajo es discutir, junto con la película, el aspecto bio-ético y político que vincula la salud, la vida y la ética; el rol de la Iglesia Católica en la vida de sus fieles; y los estereotipos de género que aparecen en las relaciones interpersonales de los personajes. Particularmente el cine, pero también los medios masivos de comunicación, muchas veces reflejan las situaciones sociales más estereotipadas, y el rol que éstas ocupan en ello, contribuyendo en su arraigo social. Por ende, utilizarlo como herramienta conceptual para poner en discusión algunas de las instituciones más enquistadas en la sociedad actual, es una apuesta más que interesante en pos de la profundización de estos análisis.
\end{abstract}

Palabras claves: Estudio del cine | Instituciones sociales | bio-ética | estereotipos de género.

\begin{abstract}
If the cinema study became a powerfull toll to understand the social analysis, this lecture brings the intention to discuss aspects of the current society and the institutional influence. The relationships of the characters are strongly crossover by the natural knowledge of the conservative middle class family in Spain below influence of the catholic religion, specifically the Opus dei. From some topic's of the Javier Fesser's film, Camino, like life, health and ethics appear in tension whit theoretical constructions in gender and biopolitic. The mass media and the cinema usually shows exacerbated stereotypes of class and gender in the social net. The analysis we pretend to offer, represent a critical view of the institutional that it shows as given, the rules we passive assume as society, the stereotype roles we accept and the relation of politics and the strongest representative institution in Iberoamerica: family and religion.
\end{abstract}

Key words: Cinema study | Social Institutions | bioethics | Gender stereotypes

\section{Introducción}

Este trabajo pretende problematizar, a partir del cine, algunos aspectos de la realidad social y las instituciones que la sostienen. Fundamentalmente, desde algunos tópicos que propone el film Camino de Javier Fesser (2008), el objetivo de este artículo es, por un lado, reflexionar en el aspecto -por momentos olvidado en la bioética- de lo político que vincula la salud, la vida y la ética; por otro lado, discutir el rol de la Iglesia Católica en la vida de sus fieles; y por último, repensar los estereotipos de género que aparecen en las relaciones interpersonales de los personajes.

Por un lado, en relación a los primeros dos objetivos, una posición fundamental del film al que nos interesa hacer referencia tiene que ver con la figura de la Iglesia Católica y el Opus Dei. Lo interesante de la trama en este aspecto, es el entrecruzamiento de las relaciones de poder que se tejen entre la religión y la medicina, la madre y el padre. En este sentido, es sugestivo prestar atención a la forma en que el rol de la Iglesia Católica denota un modo de llevar adelante la vida cotidiana, no sólo con respecto a la fe, sino a todos los aspectos que la componen. Para sus fieles, hay una forma correcta de vivir que se caracteriza fundamentalmente por un modelo de familia como institución o pilar de la sociedad.

Por otro lado, en referencia al tercer objetivo, respecto de los roles que ocupan hombres y mujeres en tanto estereotipos de género, nos interesa retomar a Gila y Guil (1999) cuando plantean que el cine es un medio de comunicación de masas privilegiado que refleja y difunde un acercamiento a la realidad $y$, por tanto, también una aproximación, una manera de entender los hombres

* mateonatacha@gmail.com

**javiermendizabalroces@hotmail.com 
y mujeres actuales (1999: 89). Con ello, se contribuye al proceso de socialización que se sostiene en la diferenciación del binomio hombre-mujer. En este sentido el cine contribuye a la formación, mantenimiento o eliminación de estereotipos, según apoyen o no las creencias aceptadas socialmente (Gila y Guil, 1999: 89).

Por lo dicho anteriormente, a través de la herramienta que el cine nos presenta, nos parece necesario aportar a la discusión respecto de las instituciones sociales tanto desde la bio-ética como desde la sociología y los estudios de género.

\section{Resumen del film}

El film Camino (2008) fue escrito y dirigido por el español Javier Fesser, inspirado en la vida de una niña de 14 años, Alexia González-Barros, fallecida en 1985 luego de 10 meses de transitar una enfermedad que la deja paralítica hasta su muerte. La película transcurre en su mayoría en Pamplona (España) durante el transcurso de la enfermedad de una niña de once años llamada Camino. Antes de enfermarse, Camino era una nena como cualquier otra, con ganas de estudiar baile y teatro (donde conoce a Jesús, un niño de su edad, que se convertirá en su primer y único amor), aunque su madre no lo permita como consecuencia de su arraigo al Opus Dei. Entre los argumentos que operarán durante todo el film sobre la subalternidad de Camino frente a la madre y la religión se encuentra en primer lugar la abnegación. Renunciar a los deseos de placer y felicidad de la vida social y pública para ofrendarlos en sacrificio divino y sumisión a las normas morales conservadoras sobre sexualidad y la capacidad de amar. Estas deben ajustarse a la devoción institucional de la familia y el matrimonio a resguardo de la esfera privada según la institución que los abarca y gobierna, la Iglesia. Cuando comienza a sentir dolores en la espalda, luego de varios diagnósticos médicos e intervenciones quirúrgicas, le descubren un tumor que le presiona las vértebras. El cáncer abre un escenario contingencial en el que el amor a Dios por sobre todas las cosas como mandato religioso dominará al extremo la vida de Camino. Si su vida cotidiana estaba antes signada por condicionamientos en las pulsiones de amor hacia la familia y el amor divino, la enfermedad la sella una misión que determina cómo será el resto de su breve vida. Esto implica además la imposibilidad de vivir y amar según las promesas de la sociedad moderna. Pese al sufrimiento en el recorrido hacia la muerte, su madre ve en ello la mano de Dios, por lo que le dice que lo ame sobre todas las cosas y que debe comprender el padecimiento como una bendición, un sendero hacia la santidad.

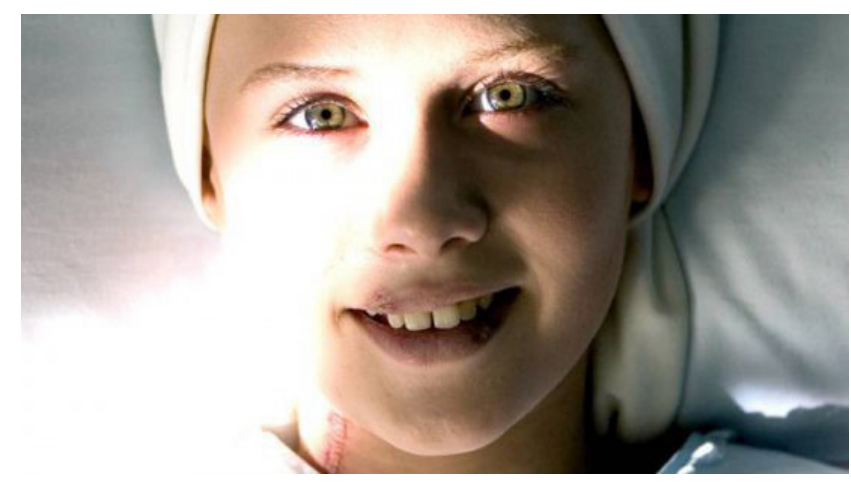

\section{Un camino entre exclusiones}

Parte clave de la trama que contextualiza el film es la presencia de la religión católica y el Opus Dei en la familia, acompañado de un sector de la sociedad conservadora española. Lejos de homogeneizar las relaciones de poder entre religión y saberes médicos, la trama se da en instituciones -familia, iglesia y hospital- donde expresamente dicha religión tiene un notable dominio, principalmente en regiones como Navarra.

Las relaciones de dominio que se entraman con visibles jerarquías entre la religión, la medicina, la familia y Camino muestran a esta última como nexo de intersección de distintas formas de administración de la vida. Esta observación precipitó el análisis a través de la biopolítica. El potencial de este término ha dado distintos desarrollos y es necesario aclarar que para el film es propicio que se lo utilice en al menos dos sentidos. El bioético que se mencionará brevemente a partir de la regulación de la vida desde dispositivos de la medicina y el otro político regulado a través de la excepción para resguardar la soberanía conformando a la comunidad política.

Así pues, este inicio puede ser analizado desde las reflexiones iniciales de Foucault (1976) en La voluntad del saber sobre el poder y sus transiciones históricas donde el poder y la soberanía transitan entre quien hace o deja, vivir o morir. Este paso no lineal en donde quien gobernara a través del poder soberano podía antes hacer morir y dejar vivir-donde la Iglesia en la inquisición, la conquista, en los hospicios ha sido actor clave- da lugar a hacer vivir y dejar morir, donde el Estado y la medicina incorporan dispositivos en sentido foucaultiano (Castro, 
2006) otorgando un carácter positivo a la gobernabilidad a través de la intervención en mejorar y prolongar la vida de las personas. La bioética cuestionará algunos aspectos de la medicalización y mercantilización de la vida dada a través de estos dispositivos. En el film pueden observarse desde el minuto 07, cuando un médico infiltra la columna de Camino por los dolores, el ejercicio de poder sobre la vida y cuestionamientos morales. El disciplinamiento violento "tengo pacientes más pequeños que son menos quejitas" y la mirada descalificadora hacia las inquietudes de la madre cuando pregunta acerca de la posibilidad de una radiografía que confirme el diagnóstico representa una limitación de la autonomía. El saber médico y la restricción de información son respuestas a los dispositivos de poder por sobre la vida, que si bien pueden entenderse desde una voluntad positiva, apelan a la disciplina pero además al control al punto de volverse incuestionable. Continuada la historia el film demuestra que el error diagnóstico no representará ninguna modificación práctica en la autonomía de la familia para cuestionar el dispositivo, Camino muere en la cama de un hospital y no en la propia. Por otro lado el dispositivo será afirmado y protegido desde el poder soberano. Cuando en el minuto 30 del film Camino es ingresada en un hospital por un desmayo y se realizan las radiografías antes negadas en el consultorio de su médico familiar los galenos se cuestionan ¿No le han hecho placas? ¿No las vieron? Incomprensible. Esta situación no rompe la red del dispositivo, hacia la soberbia del saber médico para recuperar el carácter positivo del poder sobre la vida, lo dicho y lo no dicho a los padres y lo no dicho al médico familiar son las acciones que la bioética pondrá al servicio para cuestionar por ejemplo la autonomía pero la circulación de poder dentro del dispositivo escapa a esta y requiere de una idea de la biopolítica que permita desvelar la intersección secreta entre modelo jurídico-institucional y el modelo biopolítico (Agamben, 2003:16).

Para lograr mostrar las relaciones entre la vida biológica que nos permite interactuar con el mundo natural y la vida social que le da sentido, Agamben (1996, 2003, 2004) pone a disposición su percepción propicia de la biopolítica para comprender escenas y resignificar aquello que el director propone en el devenir cronológico y la historia que hay que contar. Esta idea de biopolítica se opone al sentido de poder positivo sobre la vida que caracterizó la propuesta inicial de Foucault.

En esta línea de análisis, Paredes (2007) afirma que, a diferencia de Foucault, Agamben no subsumirá el análisis del poder a partir de acontecimientos históricos, sino que para él la biopolítica está en el centro mismo del poder soberano. Para afirmar esto Agamben (2004) se apoya en la tradición griega y el dualismo entre zoé y bios (donde el primero corresponde a la vida natural y el segundo a la vida política). En sus palabras: "politización de la nuda vida es la tarea metafísica por excelencia, en la cual se decide acerca de la humanidad del ser vivo hombre (y con ello la pertenencia, el afuera y el adentro de la comunidad humana) y, al asumir esta tarea, la modernidad no hace otra cosa que declarar su propia fidelidad a la estructura esencial de la tradición metafísica" (Agamben, 2003: 18).

En el film, la vida política que representa el poder soberano es el Opus Dei. Las leyes son las de Dios, y como tales, representan más que el poder médico. Al respecto, el inicio del film propone pensar sobre una improbable contradicción ¿Cómo un Dios de amor, misericordia y perdón puede ser indiferente ante el dolor y la muerte de una niña?

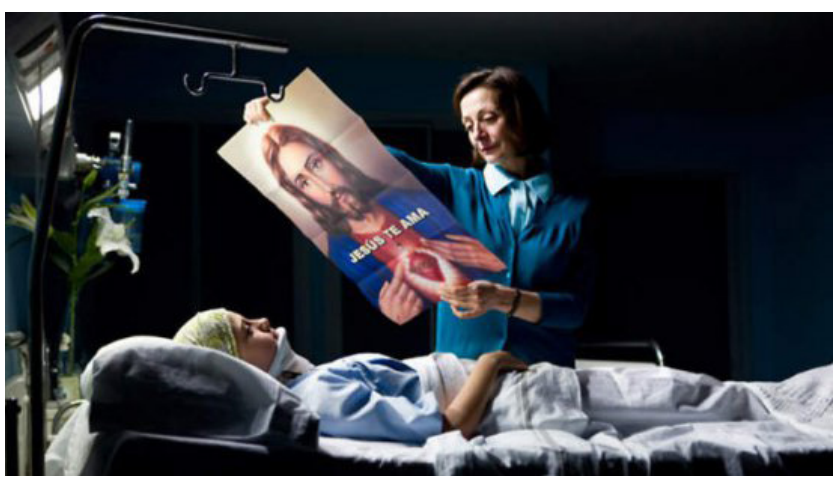

El inicio del film muestra a Camino agonizando en la cama del hospital, pero quienes protagonizan su muerte son el sacerdote de mayor jerarquía -no es el único en la habitación- y su propia madre, en un duelo de miradas que tienen como preocupación la garantía del cumplimiento normativo de la muriente para ascender a los cielos con carácter de beata.

El desenlace nos trae a la primera escena, explicitando cómo cada personaje se relaciona en el bios, o sea, la vida política religiosa. Si la hermana de Camino transitó dudas sobre el respeto a la polis y termina aceptando la voluntad de Dios, la madre sostendrá y reforzará las normativas de la ley divina para garantizar el poder soberano, mientras que el padre no encontrará posibilidades de salir de la sumisión que la misma ley impone. En el caso de Camino, las pruebas a las que su salud y la polis le presentan, generan un tránsito entre aceptación o rechazo de la ley divina, y aceptación o rechazo del sufrimiento y muerte a temprana edad. 
Por ende, para garantizar el poder soberano -desde la Iglesia- y superar la contradicción del castigo de la muerte y el amor de Dios, es necesaria una excepción que le permita resguardar la ley divina. Al respecto, Agamben sostiene que la excepción soberana es "el dispositivo original a través del cual el derecho se refiere a la vida y la incluye dentro de sí por medio de la propia suspensión" (2004: 24).

La exceptio que debe suspenderse requiere que Camino se convierta en zoé. Así su cuerpo enfermo, doloroso y muriente se convierte en un mero cuerpo. Es decir, el medio para un fin que garantice la ley divina: la posibilidad de proyecto de santificación de Camino.

Este proyecto se manifiesta entonces, en la producción del homo sacer a través de la declaración del estado de excepción; la nuda vida es el producto de la decisión soberana.

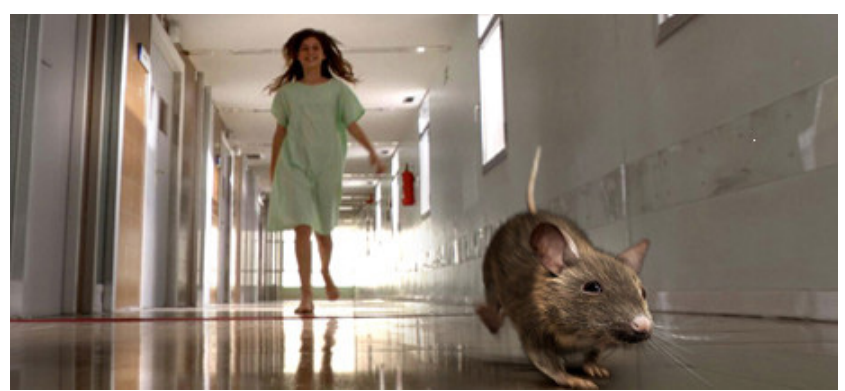

De alguna manera, el cuerpo y la enfermedad -que en el minuto 98 del film la madre confiesa "yo le agradezco todos los días la enfermedad de nuestra hija (a Jesús)"se reduce a zoé y puede legitimizarse en ella a través de una excepción. La exclusión de bios -su joven y devota hija- disipa las dudas dogmáticas del amor de Dios que, como leyes divinas, pueden sobrevivir en la excepción incluyendo la prometedora canonización de ese cuerpo. Puntualmente, en el caso de Camino será elegir el amor como indiferencia ante el hecho de su muerte inminente, el derecho divino y/o decidir por su propia vida, o dicho de otra forma, la posibilidad de percibirlo en algunos momentos como un castigo.

Esta excepción soberana en el film Camino expone otra de las observaciones realizadas por Agamben (2003, 2004). Se presenta el paradigma de la sacralización de los cuerpos como un hecho singular, que tanto puede pensarse en el tejido entre el bios y vivir la polis que involucró a los protagonistas como excepción y por otro lado la posibilidad de pensarlo en ejemplo común de todas aquellas personas candidateadas a la santidad. Para Agamben el exiliado, el comatoso, el sujeto experimental comparten esta característica y "pierden su condición de ciudadanos con derechos, que los refugiados se convierten, en términos de Agamben, en "hombres sagrados" (bomo sacer), en el sentido que tenía este término en el derecho romano arcaico: consagrado a la muerte (Berrío, 2010:28).

Esta característica común muestra la relación entre la ley suspendida en Camino de amor divino y justificación de sufrimiento y muerte que puede observarse en un comatosos irreversible conectado a un respirador garantizando vida nuda y los obstáculos médico legales en la finalización de la vida -cualificada- y la situación que afronta un refugiado y aquella que Agamben desarrollará en el campo de concentración. De esta forma la política occidental puede entenderse desde sus inicios como biopolítica.

Lo excepcional de esta pieza es que el mismo director ha reconocido que, si bien se inspiró en un caso real, las variaciones realizadas responden a entrecruzar la historia con otras pequeñas escenas de otros candidatos/ as. La escena final en la cual un sacerdote despide la muerte gloriosa de Camino con un emotivo aplauso es traída de la emoción pero de otra contemplación de una aspirante a la santidad. ${ }^{1}$ Según Agamben, el ejemplo es una singularidad entre las demás, pero que está en lugar de cada una de ellas, que vale por todas (1996: 13).

La norma de beatificar a todos/as los/as niños/as devotos y sufrientes/agonizantes no es ley que pueda ser aceptada de forma pasiva en la sociedad religiosa. ${ }^{2}$ Por lo tanto, en este caso el estado de excepción "beata" opera en dos sentidos. En un primer lugar, desde la percepción de la madre y el Opus Dei, en poder aceptar el sufrimiento y la propia muerte de su hija. En cambio, en un segundo lugar, le da soberanía a Camino a través de la posibilidad de proyectarse en sueños y así escapar de las leyes del orden religioso y de la vida biológica que la devora.

Justamente, esta tensión que propone la proyección de las imágenes es la misma que Agamben (2003, 2004) intenta exponer como explicativas de la construcción política moderna. El ejemplo o paradigma cristaliza el estado de excepción para hacerlo regla y esto permite al soberano reorganizar y consolidar su poder.

Por lo tanto, primero fue necesario entender el castigo divino como excepción que esté incluida en los valores morales coherentes a la vida devota de Camino a través del proyecto de beatificación pero que en realidad no forma parte de ella. Sus suspiros y anhelos son la excepción que Camino ha construido en base a un amor soñado con un niño fuera de la opresión religio- 
sa. Segundo el ejemplo de padecimiento, sufrimiento y abnegación tiene posibilidad de excluirse como hecho real si se resume a Camino como un objeto/instrumento de manifestación de Dios. De alguna forma este hecho singular imprime cierta universalidad que ha podido ser paradigma de santidad. Aquellos que sufren lo suficiente por Dios, más que por amor, en el bios pueden reducirse a la vida natural para darle sentido a la ley divina y no desestabilizar al poder soberano.

De alguna manera, este ejemplo puede explicar los acontecimientos históricos alrededor de los procesos de santificación en el mundo. En este sentido, podríamos arriesgar que el proceso de santificación propuesto en Camino puede ser pensado como paradigma, no por ser similar a otros hechos de beatificación, sino por convertir en regla a la excepción. Al respecto, el próximo apartado propone poner en discusión cómo este proceso de santificación se pone en tensión entre lo real y lo ficticio.

\section{La beatificación: discusiones entre ficción y realidad}

Aunque la película esté basada en hechos reales, no implica que los reconstruya fehacientemente. Por lo tanto, existen algunas diferencias entre la vida y la enfermedad Alexia, y la vida y la enfermedad de Camino. Éstas no son un detalle menor, ya que han generado varios conflictos sobre los que nos interesaría hacer referencia con el fin de complejizar y comprender todo los ámbitos a los que se circunscribe un film, por fuera de los 143 minutos que dura el mismo.

Fundamentalmente, quisiéramos retomar una de las propuestas que realiza la película para profundizar el análisis: el rol de la Iglesia Católica en la vida de sus fieles. Aunque ya fuimos mencionando algunos aspectos en las páginas anteriores, quisiéramos puntualizar en cómo la asunción de esta conducta por parte de dicha institución ha generado conflictos entre el director y la familia de Alexia.

Para comenzar, toda la densidad de la situación que muestra la película en tanto Camino transita los días hasta su muerte, está atravesado por el contraste entre las luces y las sombras, una fotografía magnífica a cargo de Alex Catalán y una Banda Sonora a la altura de las expectativas. Más allá de su presencia ejemplar en todo el film, aparecen con especial énfasis en los sueños de Camino, operando a modo de quiebre entre los deseos de la niña y sus temores.
Asícomo en otros films, los sueños de Camino rompen con lo real de su situación. En este sentido, trascienden lo meramente posible, e interpelan al espectador desde otro lugar, en donde los sueños se vuelven pesadillas. Éstos son la forma en que se materializan y vuelven explícitos para la niña los conflictos que se suceden en su vida, sobre todo, en relación a su madre, una ferviente católica perteneciente al Opus Dei, con la necesidad imperiosa de controlar todos los aspectos de la vida de su hija para que encuentre la senda de Dios.

En este sentido, la religión, encarnada en la figura de su madre, se contrapone constantemente con los deseos de Camino. Esto se puede ver desde lo más simple como la compra de un libro hasta la obligación maternal de agradecer el sufrimiento de la enfermedad a Dios. Las contradicciones entre los deseos de la niña y las imposiciones de su madre, aparecen en sus sueños, superando las dicotomías, representando la forma en que las tensiones entre ambos, que en apariencia no le afectan, tienen consecuencias terribles en su inconsciente.

Más allá de los sueños y su impecable calidad fílmicoestética, es fundamental también hacer referencia a la película como un espacio de disputa constante, como un campo donde lo simbólico entra en tensión en términos de Bourdieu. Tanto el arte, como la religión, la ciencia y la cultura, forman parte de estos espacios de disputa de sentido, donde las relaciones de poder se vuelven símbolos. En este aspecto, Fesser intenta con la película pugnar el campo de la religión desde el arte, construyendo una clara crítica al Opus Dei en tanto institución.

Una apuesta en este sentido, es la crítica en torno a la beatificación de la niña. ¿Cuáles son los requisitos que impone la Iglesia Católica para ser considerado Beato? Para poder adentrarnos en estos temas, la página web realizada a modo de difusión sobre la vida de Alexia (el caso real de la niña que inspira la película) aclara que para proponer seriamente una canonización es necesaria la fidelidad a Dios de una vida, pero [también] la Iglesia pide más, y exige, como condición necesaria, una señal de Dios: que de forma espontánea surja lo que se llama 'fama de santidad'. Tras el fallecimiento de Alexia el 5 de diciembre de 1985, su fama de santidad surgió de forma inmediata y espontánea, y desde entonces se ha ido incrementando constantemente. ${ }^{3}$ Con ese fin, al hacer referencia a su vida, en la página se la muestra como una niña común, feliz, fiel creyente, con el objetivo de reforzar la idea de su devoción por la Iglesia Católica. Esta referencia es llevada al extremo de afirmar que Alexia fue un ejemplo de lo que san Josemaría enseñó 
durante toda su vida: que todos podemos ser santos en la normalidad de nuestra vida cotidiana. ${ }^{4}$

En esta línea, la película mostró la forma que adquieren las relaciones interpersonales y las relaciones de poder que se ejercen desde el Opus Dei, una de las instituciones más influyentes y cuestionadas de la Iglesia Católica. Sin embargo, es sumamente interesante pensar cómo una institución tan antigua como ésta se siente vulnerada con la película. Aunque en una entrevista Fesser afirmó que pasó tres días viviendo en un monasterio para comprender mejor a la Iglesia desde su cotidianidad, esto no bastó para que llovieran las críticas.

Las reacciones no se hicieron esperar, y en un comunicado de prensa, proveniente de la Oficina de Información del Opus Dei en España, el 18 de octubre de 2008, afirmaron que presenta la fama de santidad de la niña como una manipulación del Opus Dei. ${ }^{5}$

En el mismo escrito, también cuestionaron la forma en que la película muestra la institución: El Opus Dei real es muy distinto del que se presenta en esa ficción. Quienes tienen una experiencia directa, saben que sus miembros no son ni se creen superhombres, sino gente normal, con sus virtudes y sus defectos, cada uno con su personalidad y carácter, que procuran vivir con bumanidad, cordialidad y comprensión. Cualquier persona sensata rechaza el panorama que aparece en la película; un esperpento que no corresponde con la verdad del Opus Dei. ${ }^{6}$

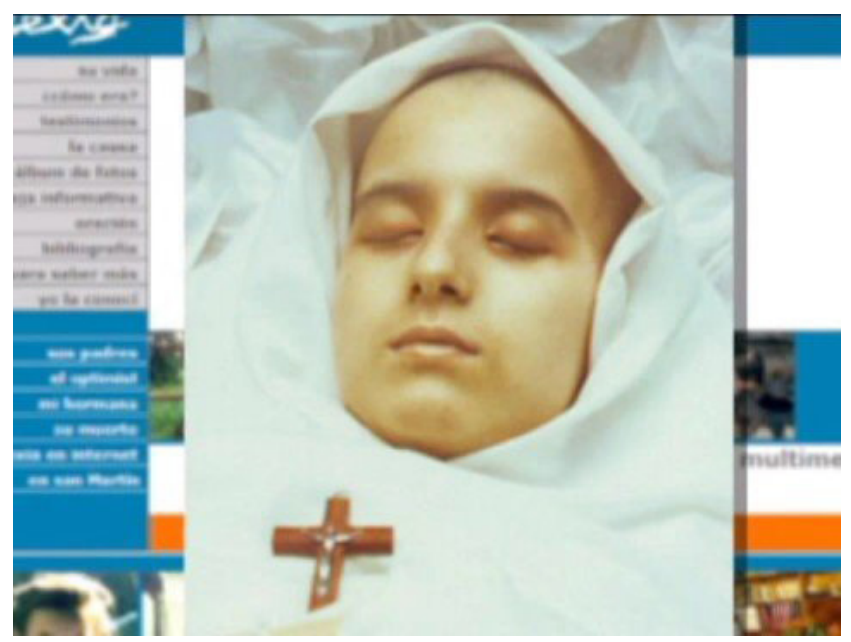

Desde otro lugar, pero con el mismo énfasis, sucedieron las críticas de la familia. Particularmente, uno de los hermanos de Alexia tomó el rol del vocero familiar y cruzó opiniones con el director, acusándolo de varias maneras, pero sobre todo con referencia a la escena de la muerte de su hermana. En esa parte crucial de la película, donde Camino es ovacionada y aplaudida, en lo que para Fesser fue un sentido homenaje, para la familia constituyó una falta de respeto. Por ello, en una carta pública que le envía el hermano de Alexia al guionista le dice que No debería hacer falta que te diga que mi hermana Alexia no murió rodeada de aplausos. Murió rodeada de cariño. Cariño de sus seres queridos: padres $y$ hermanos $y$, con el silencio respetuoso de las enfermeras, doctores y enfermos que 'motu propio' se acercaron a la babitación de Alexia?

Más allá de las críticas que se suscitaron tanto del Opus Dei como de la familia, es interesante analizar cómo el director, por la obligación ética de preservar la identidad de la niña (al estar la película basada en hechos reales) la titula Camino: el nombre del libro más importante escrito por San Josemaría (1902-1975), fundador del Opus Dei. Este detalle no es menor, ya que genera una línea paradójica entre la santificación de Camino (la niña) y la santificación del libro, dando cuenta de cómo el Opus Dei se presenta también como una verdad espiritual y absoluta. Esto se puede ver a partir de los debates que abrió la película que se mencionan anteriormente. El libro Camino, se presenta a partir del siguiente rezo: Lee despacio estos consejos. Medita pausadamente estas consideraciones. Son cosas que te digo al oído, en confidencia de amigo, de hermano, de padre. Y estas confidencias las escucha Dios (2001[1939]). Publicado en 1939, consta de 999 puntos de meditación personal abordando distintos criterios de la vida cristiana.

\section{Los estereotipos de género en el film}

Por último, nos interesa hacer referencia a otra de las críticas que aparece en la película a partir de la perspectiva de género. Esta perspectiva nos permite analizar cómo se expresan las diferencias de apropiación de los recursos materiales, culturales y simbólicos para mujeres y hombres; al mismo tiempo que provee las herramientas teóricas, conceptuales y metodológicas para un análisis de la realidad social que permite observar la materia en que se estructuran los dualismos y jerarquías de género, y cómo estas construcciones y conceptualizaciones de género inciden en nuestra forma de pensamiento, nuestros métodos de conocimiento y el lenguaje con que nombramos y significamos la realidad. Como categoría de análisis, el género explica los factores que conducen a las desigualdades entre mujeres y hombres, al mismo tiempo que pone de manifiesto el carácter jerarquizado de las relaciones entre los sexos, construidos en cada cultura (Fabbri, 2013). 
Desde esta óptica, nos centramos en el rol que ocupan hombres y mujeres en relación con los estereotipos de género. Por un lado, la inversión de estos estereotipos entre los padres de Camino, y por otro lado, el rol que ocupa la hermana de Camino en el Convento reforzando estos estereotipos.

Para comenzar, es fundamental hacer referencia a los debates y discusiones que llevaron adelante los grupos feministas de los años '60 y '70 en Argentina, con la intención de discutir el papel central de la mujer en la sociedad a partir de la maternidad. Para las feministas, esta asociación mujer-madre se sostenía en un pilar fundamental que había que derribar: el patriarcado como base del sistema capitalista moderno que generaba la subordinación de las mujeres. ${ }^{8}$

El postulado de la construcción de la diferencia sexual jerarquizada se remonta a los orígenes de la civilización occidental, donde aparece una dicotomía entre hombre y mujeres, en la cual el hombre está asociado a la cultura y la mujer a la naturaleza en función de su sexualidad y fertilidad (Foucault, 1977; Fausto-Sterling, 2000; Rubin, 1989). En este sentido, Luciano Fabbri (2013) afirma que la fetichización biológica es uno de los pilares de la ideología patriarcal, ya que es internalizada por los sujetos de forma tal que actúa sobre la autoconciencia, impidiendo su cuestionamiento. El carácter supuestamente neutral y objetivo de las ciencias naturales y su metodología aséptica de investigación funciona como punta de lanza de esta ideología (Fabbri, 2013: 78).

La intención de las teóricas feministas de los '60 y '70 fue justamente desenmascarar y denunciar el patriarcado como un sistema de opresión social, cultural y económica donde las diferencias sexuales que se asumían como biológicas y naturales sostenían la subordinación de las mujeres a la dominación masculina (Millet, 1975; Paterman, 1995; Lerner, 1990).

Dentro de esta línea de análisis, muchas características se cristalizan en los estereotipos de hombre y mujer asociados a roles definidos que se impregnan en la sociedad. En este sentido, coincidimos con quienes consideran que las imágenes cinematográficas tienen en la actualidad indiscutibles efectos sobre la construcción del sistema sexo/género [...] Es un soporte perfecto para realizar una proyección de la realidad (Gila y Guil, 1999: 91).

Sin embargo, en la película aparece una inversión de roles respecto de los estereotipos de género, ya que podemos ver una madre autoritaria y un padre com- prensivo. La madre, aunque ocupa la figura de cuidadora, aparece más inmersa en una estructura matriarcal, donde es ella quien toma las decisiones, asesorada por los dos sacerdotes, mientras que el padre ocupa el rol de contenedor, preocupado por la felicidad de la niña, que no coincide con las decisiones de la madre pero que tampoco logra imponer sus propias opiniones al respecto.

Esta falencia para contradecir a la madre de Camino, aparece muy claramente en la relación que éste tiene con Nuria, la hermana. En una primera instancia, ella aparece como personaje definido por su vocación de servicio a Dios, pero luego va emergiendo, en forma de anécdotas que cuentan otros personajes, un pasado muy distinto donde ella estaba enamorada de un joven (tipificado como artista o músico) que no se comunicó al momento de emprender un viaje por lo que tomó la decisión de iniciar el camino de Dios en el Convento. El amor entre Nuria y este joven emerge en reiteradas ocasiones simbolizando el amor que siente Camino por Jesús (el niño de su edad del cual está enamorada), y cómo ella ve en la relación fallida de la hermana, el amor que ella quisiera también poder sentir, pero que no va a poder ser debido a su enfermedad. Sin embargo, en medio de la película, el padre encuentra que la madre había interceptado y guardado esas cartas (finalmente existentes) bajo llave. El quiebre que genera esa escena en que el padre encuentra las cartas que la madre censuró, da cuenta de la forma que el director encontró para homologar la enfermedad que se interpone entre Camino y Jesús, con la madre interponiéndose al amor entre la hermana y su novio. Esta homologación aparece como uno de los ejes en que Fesser discute la intervención de la Iglesia Católica, en este caso el Opus Dei, en la vida de sus fieles, imponiendo en la vocación una forma de llevar adelante la vida y transitar por el mundo, contraria (en algún punto) a los deseos de cada uno, o en verdad, imponiendo un camino que obstaculiza el deseo.

Y por último, aparece claramente los roles que cumplen hombres y mujeres dentro del Convento. Este contraste se lleva al extremo, al punto en que los hombres pueden presenciar la misa, mientras que las mujeres sólo pueden ver al Sacerdote que la lleva adelante a través de una ventana; o en el hecho en que las mujeres sirven todas las comidas para los hombres y esas habitaciones sólo se comunican por una puerta que está cerrada con llave imposibilitando siquiera que se vean. 


\section{Conclusiones}

En síntesis, el trabajo se propone mostrar cómo un film es susceptible de ser analizado desde diferentes ópticas: la psicología, la filosofía, la sociología, la comunicación, etc. Lo interesante es poder ir más allá de la película en sí misma, incluso trascender la propuesta del director.

Analizar la realidad social a partir del cuestionamiento sobre los medios de comunicación (en este caso el cine) es fundamental para poder complejizar los debates que se proponen desde las ciencias sociales. Claramente este trabajo no abarca la totalidad de los tópicos que emergen en la película. Sin embargo, intenta utilizar como puntapié del análisis algunas de las propuestas del guionista y director, para comprender el rol que ocupan tanto la Iglesia Católica (a partir del Opus Dei) como institución, los estereotipos de género en la forma en que los distintos personajes se construyen y relacionan, y los aspectos bioéticos que emergen.

Por un lado, nos parece fundamental considerar que, como la película está basada en hechos reales, los debates que se suscitaron posteriormente entre el director, el Opus Dei y la familia, dan cuenta del poder que tienen los medios de comunicación en la vida cotidiana de las personas.

Por otro lado, es fundamental remarcar que cuando los derechos ciudadanos de las personas deben ofrecerse a la voluntad divina y aparecen en contraposición a los valores de misericordia y amor divino, cuando el dolor y el padecimiento deben proponerse como actos de amor; requieren por excepción dar lógica y garantizar, a pesar de ello, al poder soberano. Esta condición hecha regla para el proceso de santificación constituye una radicalización biopolítica que desde lo singular se presenta indiscernible entre los hechos y el derecho. Así, se muestra a Camino incluida en el ejemplo pero excluida al morir bailando con su amado lejos de añorar la santidad. Al mismo tiempo, su hermana continúa su carrera religiosa abandonando sus dudas y el reducto de su vida pública, su madre materializa todos los ritos que normaticen la vida natural a la cual se ha sometido el cuerpo de Camino llevando el ataúd ante sus amigos y dándole sepultura. En el caso del padre, la sumisión le había garantizado pertenecer a la vida política familiar y de su comunidad, pero cuando al fin alcanza esa doble negación que Cami- no abraza entre sueños para superar morir u ofrecer morir como acto divino un accidente lo reduce a zoé. La muerte cancela el derecho a resignificar la agonía de Camino y el divorcio inminente, ambos amenazantes al hecho: el proceso de santidad.

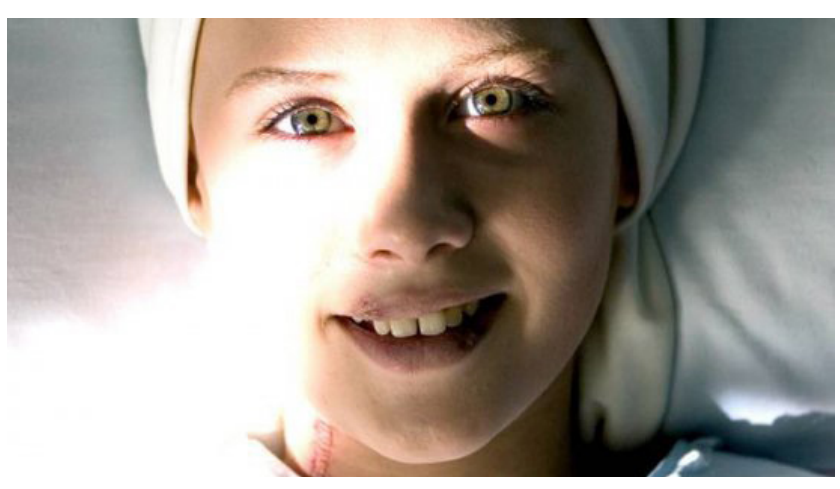

La construcción política sobre la vida no ha recibido aún interpelaciones de los procesos de santidad dentro de la propia institución. Esta falta de conflicto puede deberse a la aceptación de la excepción como regla. En primer lugar, la exclusión dentro de la vida política que es inclusiva dentro del proceso santificación y, en segundo lugar, la inclusión de este singular en el proceso de santificación como excluido de un ejemplo particular.

En definitiva, el film es una posibilidad de observar de que manera la política y la vida aparecen en un acontecimiento singular pero pueden pensarse tanto como ejemplo particular o constitutivo de lo universal. El hecho de que se nos presente a través de la ficción fragmentos de historias reales tejidas en un todo donde las tragedias aumentan y se superponen, permite resignificar el comienzo de la proyección fuera del proyecto de santificación y fuera de la muerte. Este giro permite de alguna manera aliviar las tensiones entre religión y las enfermedades terminales y hace permeable pensar en transformaciones de la realidad que aparecen ajustadas a una forma de afrontar los opuestos. El poder soberano opera a través de la biopolítica para poder normatizar la vida y darle sentido dentro de la misma organización política y así gestionar gobernabilidad. En este sentido, Camino muestra la capacidad de intervención de la biopolítica para sostener el poder soberano y, de alguna manera, la protagonista nos sugiere una salida como derrame silencioso y personal a modo de política de la vida por sobre este poder. 


\section{Referencias}

Agamben, G. (1996) La comunidad que viene, España: Pre-textos.

Agamben, G. (2003) Homo sacer. El poder soberano y la nuda vida. Valencia: Pre-Textos.

Agamben, G. (2004) Estado de excepción. Homo sacer II, Buenos Aires: Adriana Hidalgo.

Berrío, Ayder (2010) La exclusión-inclusiva de la nuda vida en el modelo biopolítico de Giorgio Agamben: algunas reflexiones acerca de los puntos de encuentro entre democracia y totalitarismo. Estudios Políticos, 36, 11-38.

Castro, E. (2006) Michel Foucault: Sujeto e historia. Tópicos. Santa Fe. 14, 171-183.

Fabbri, L. (2013) Apuntes sobre feminismos y construcción de poder popular. Argentina: Puño y letra.

Fausto-Sterling, A. (2000) Cuerpos sexuados: la política del género y la construcción de la sexualidad. España: Editorial Melusina.

Foucault, M. (1977) Historia de la sexualidad 1: La voluntad del saber. Argentina: Siglo XXI Editores.

Foucault, M. (1986) Historia de la sexualidad 2: El uso de los placeres. México: Ed. Siglo XXI.

Gila, J. y Guil, A. (1999) La mujer actual en los medios: estereotipos cinematográficos. En Comunicar: Revista científica iberoamericana de comunicación y educación, $\mathrm{n}^{\circ} 12$.

Josémaría Escrivá de Balaguer (2001). Camino. España: Ediciones Rialp.

Lerner, G. (1990) La creación del patriarcado. España: Editorial Crítica.

Millet, K. (1975) Política Sexual. México: Ed. Aguilar.

Paredes, D. F. (2007) El paradigma en la biopolítica de Giorgio Agamben. En Lopoldo Múnera (ed.). Normalidad y excepcionalidad en la política (Schmitt, Agamben, Žižek y Virno) (pp.109-124). Universidad Nacional de Colombia, Sede Bogotá: UNIJUS.

Pateman, C. (1995) El contrato sexual. Madrid: Ed. Anthropos.

Rubin, G. (1989) Reflexionando sobre el sexo: notas para una teoría radical de la sexualidad. En Vance, C. (comp.) Placer y peligro. Explorando la sexualidad femenina. España: Editorial Revolución.

1 En el próximo apartado haremos referencia a los entrecruzamientos entre la ficción y la realidad.

2 En el próximo apartado también haremos referencia al respecto.

3 http://www.alexiagb.org/web/causa.htm Consultado el 27/07/2016

4 http://www.alexiagb.org/web/suvida.htm Consultado el 27/07/2016

5 http://multimedia.opusdei.org/pdf/e... Consultado el 26/07/2016

6 http://multimedia.opusdei.org/pdf/e... Consultado el 26/07/2016

7 http://www.alexiagb.org/web/alfredo.htm Consultado el 27/07/2016

8 Siguiendo estos debates feministas, entendemos por patriarcado a la organización social jerarquizada de los sexos basada en la dominación masculina sobre las mujeres, construyendo así una red de poder que se asienta y perpetúa en la tradición de un discurso biológico cristalizado en la legitimación de una diferenciación social. 